\title{
Collimonas fungivorans gen. nov., sp. nov., a chitinolytic soil bacterium with the ability to grow on living fungal hyphae
}

\author{
Wietse de Boer, ${ }^{1}$ Johan H. J. Leveau, ${ }^{1}$ George A. Kowalchuk, ${ }^{1}$ \\ Paulien J. A. Klein Gunnewiek, ${ }^{1}$ Edwin C. A. Abeln, ${ }^{2}$ Marian J. Figge, ${ }^{2}$ \\ Klaas Sjollema, ${ }^{3}$ Jaap D. Janse ${ }^{4}$ and Johannes A. van Veen ${ }^{1}$ \\ ${ }^{1}$ Netherlands Institute of Ecology, Centre for Terrestrial Ecology, Department of \\ Plant-Microorganism Interactions, NL-6666 ZG Heteren, the Netherlands \\ ${ }^{2}$ Netherlands Culture Collection of Bacteria, NL-3584 CT Utrecht, the Netherlands \\ ${ }^{3}$ Eukaryotic Microbiology, Groningen Biomolecular Sciences and Biotechnology Institute, \\ University of Groningen, NL-9751 NN Haren, the Netherlands \\ ${ }^{4}$ Plant Protection Service, Section Bacteriology, NL-6700 HC Wageningen, the Netherlands
}

Correspondence Wietse de Boer w.deboer@nioo.knaw.nl
A polyphasic approach was used to describe the phylogenetic position of 22 chitinolytic bacterial isolates that were able to grow at the expense of intact, living hyphae of several soil fungi. These isolates, which were found in slightly acidic dune soils in the Netherlands, were strictly aerobic, Gram-negative rods. Cells grown in liquid cultures were flagellated and possessed pili. A wide range of sugars, alcohols, organic acids and amino acids could be metabolized, whereas several di- and trisaccharides could not be used as substrates. The major cellular fatty acids were $\mathrm{C}_{16: 0 \text {, }}$ $\mathrm{C}_{16: 1} \omega 7 c$ and $\mathrm{C}_{18: 1} \omega 7 c$. DNA G+C contents were 57-62 mol\%. Analysis of nearly full-length $16 \mathrm{~S}$ rDNA sequences showed that the isolates were related closely to each other $(>98.6 \%$ sequence similarity) and could be assigned to the $\beta$-Proteobacteria, family 'Oxalobacteraceae', order 'Burkholderiales'. The most closely related species belonged to the genera Herbaspirillum and Janthinobacterium, exhibiting 95.9-96.7\% (Herbaspirillum species) and 94.3-95.6\% (Janthinobacterium species) 16S rDNA sequence similarity to the isolates. Several physiological and biochemical properties indicated that the isolates could be distinguished clearly from both of these genera. Therefore, it is proposed that the isolates described in this study are representatives of a novel genus, Collimonas gen. nov. Genomic fingerprinting (BOX-PCR), detailed analysis of $16 S$ rDNA patterns and physiological characterization (Biolog) of the isolates revealed the existence of four subclusters. The name Collimonas fungivorans gen. nov., sp. nov. has been given to one subcluster (four isolates) that appears to be in the centre of the novel genus; isolates in the other subclusters have been tentatively named Collimonas sp. The type strain of Collimonas

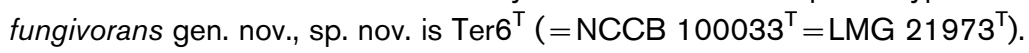

Published online ahead of print on 28 November 2003 as DOI 10.1099/ijs.0.02920-0.

Abbreviation: FISH, fluorescent in situ hybridization.

The GenBank/EMBL/DDBJ accession numbers for the 16S rDNA sequences of strains Ter6 ${ }^{\top}$, Ter331, Ter118/Ter113, Ter227/Ter72, Ter14, Ter90, Ter91, Ter94, Ter165, Ter166, Ter266, Ter282, Ter291, Ter299, Ter300, Ter10, Ter146, Ter228, Ter252 and Ter330 are AJ310394, AJ310395, AJ496444, AJ496445 and AY281135AY281150, respectively.

Physiological characteristics of the Ter isolates, respiratory responses to four Biolog substrates and chitosan, an unrooted phylogenetic tree based on 16S rDNA sequences and a UPGMA cluster analysis of BOX-PCR-generated genomic fingerprints are available as supplementary material in IJSEM Online.

\section{INTRODUCTION}

The ability of soil bacteria to produce chitinases is commonly indicated by the formation of clear zones (haloes) on agar plates that contain colloidal chitin (Gooday, 1990). This halo-forming ability is also the basis for enumeration of culturable chitinolytic bacteria. By using this method, it was observed that the dominant chitinolytic bacteria in slightly acidic dune soils in the Netherlands formed haloes with translucent colonies of little biomass on minimal chitin agar (De Boer et al., 1998).

Twenty-two of these chitinolytic isolates were tested for their ability to degrade particulate chitin in sand; they were 
poor degraders compared to filamentous fungi, actinomycetes and gliding bacteria (De Boer et al., 1999). Further study revealed that these isolates could use their chitinase activity to facilitate mycoparasitic growth, i.e. growth at the expense of living fungal hyphae (De Boer et al., 2001). Based on whole-cell fatty acid analysis, these isolates were identified provisionally as belonging to the genus Pseudomonas of the $\gamma$-Proteobacteria (De Boer et al., 1998). However, preliminary $16 \mathrm{~S}$ rDNA sequence analysis subsequently revealed that they were affiliated to the $\beta$-Proteobacteria (De Boer et al., 2001). Here, results of polyphasic taxonomic characterization of these isolates are presented; these results support their classification in a novel genus, Collimonas gen. nov.

\section{METHODS}

Bacterial isolates. Isolates $(n=22)$ were taken from chitin agar plates of samples of slightly acidic dune soils located on the Wadden Island Terschelling, as described previously (De Boer et al., 1998). The isolates, referred to as Ter isolates, were stored at $-80^{\circ} \mathrm{C}$ and maintained on chitin/yeast agar and $0 \cdot 1 \times$ tryptone soy broth (TSB; Oxoid) agar for routine culturing. Both media contained $\left(1^{-1}\right): 1 \mathrm{~g}$ $\mathrm{KH}_{2} \mathrm{PO}_{4}, 5 \mathrm{~g} \mathrm{NaCl}$ and $20 \mathrm{~g}$ agar. In addition, $0 \cdot 1 \times \mathrm{TSB}$ agar contained $3 \mathrm{~g} \mathrm{TSB} \mathrm{l}^{-1}$ and chitin/yeast agar contained $2 \cdot 0 \mathrm{~g}$ colloidal chitin $1^{-1}$ and $0.05 \mathrm{~g}$ yeast extract (Difco) $1^{-1}$. Media were adjusted to $\mathrm{pH} 6 \cdot 5$ with $1 \mathrm{M} \mathrm{NaOH}$ before autoclaving. Colloidal chitin was prepared as described by Hsu \& Lockwood (1975) from crab-shell chitin (Sigma).

As it appeared that the $16 \mathrm{~S}$ rDNA sequences of the isolates were related most closely to those of members of the genus Herbaspirillum, three Herbaspirillum type strains (Herbaspirillum seropedicae DSM $6445^{\mathrm{T}}$, Herbaspirillum rubrisubalbicans ATCC $19308^{\mathrm{T}}$ and Herbaspirillum frisingense DSM $13128^{\mathrm{T}}$ ) were included in some parts of the study (metabolic profiling and cellular fatty acid composition) for comparison.

Phenotypic characterization. Gram-reaction was tested indirectly by determining lysis in $\mathrm{KOH}$. Motility was tested by measuring the spread of cells inoculated into $0 \cdot 1 \times$ TSB that contained $0 \cdot 2 \%$ agar. Colony morphology of cells grown at $20^{\circ} \mathrm{C}$ on $0 \cdot 1 \times$ TSB agar (3 days) was assessed. Cellular morphology of five isolates $\left(\mathrm{Ter}^{\mathrm{T}}\right.$, Ter146, Ter227, Ter252 and Ter331), representing different colony forms, was studied by using a Philips CM10 transmission electron microscope.

Whole-cell fatty acid composition was determined after growth for $48 \mathrm{~h}$ at $28^{\circ} \mathrm{C}$ on full-strength TSB agar by using the Microbial Identification system (Microbial ID). Extraction and preparation of fatty acid methyl esters, chromatography, reference library generation and principal component and cluster analyses were performed as described by Janse (1991).

Ability to oxidize various carbon sources was tested by using Biolog GN plates. Presence of oxidase was determined by using a test card (bioMérieux). Catalase activity was checked by holding a loop of bacterial cells in a drop of $3 \%$ hydrogen peroxide solution on a microscopic slide. Direct appearance of gas bubbles indicated the presence of catalase. Chitosanase, $\beta$-glucanase, cellulase and protease activities were assayed visually, i.e. by production of clear zones after 2-3 weeks at $20^{\circ} \mathrm{C}$ on plates that contained $2 \%$ agar and $\left(1^{-1}\right): 1 \mathrm{~g}$ $\mathrm{KH}_{2} \mathrm{PO}_{4}, 5 \mathrm{~g} \mathrm{NaCl}$ and $0.05 \mathrm{~g}$ yeast extract (pH 6.5). Colloidal chitosan was obtained by preparing water-soluble chitosan from crab chitosan (Sigma) and mixing it to a final concentration of $0 \cdot 2 \%$ with a hot agar/salt solution. Lichenan (Sigma) was used as the substrate $(0 \cdot 1 \%$ final concentration) for indicating glucanase activity (Walsh et al., 1995). Glucanolytic haloes were visualized after staining with Congo red. Cellulose agar contained $2 \%$ cellulose powder (Sigma). Protease activity was demonstrated by using milk agar, which contained $3 \%$ skimmed milk.

Ability to hydrolyse colloidal chitin was tested in both minimal agar and agar mixed with TSB $\left(3 \mathrm{~g} \mathrm{l}^{-1}\right)$. In addition, ability of the isolates

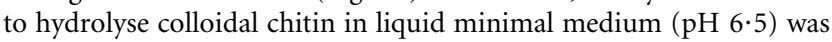
tested by measuring the release of $\mathrm{NH}_{4}^{+}$.

Effects of $\mathrm{pH}$ and temperature on growth were studied in four isolates: one representative of each of the three colony types that were observed (Ter146, Ter227 and Ter331; see Results and Discussion) and the proposed type strain $\left(\mathrm{Ter}^{\mathrm{T}}\right)$. Optimum $\mathrm{pH}$ for growth in minimal liquid medium was $5 \cdot 0-8 \cdot 0$, using the ethanesulfonic acid buffers (10 mM; Sigma) MES (pH 5.0, 5.5, 6.0 and 6.5) or HEPES $(\mathrm{pH} 7 \cdot 0,7 \cdot 5$ and $8 \cdot 0)$. For determination of temperature optimum and tolerances, minimal medium that contained $10 \mathrm{mM}$ MES $(\mathrm{pH} 6 \cdot 5)$ was used. The growth substrate in both experiments was $\mathrm{N}$-acetylglucosamine $(2 \mathrm{mM})$. Growth was recorded by measurement of $\mathrm{OD}_{660}$.

Tolerance to antibiotics was tested by growing the isolates on TSB agar that contained one of the following compounds: ampicillin (20 and $60 \mu \mathrm{g} \mathrm{ml}^{-1}$ ), streptomycin (25 and $50 \mu \mathrm{g} \mathrm{ml}^{-1}$ ), oxytetracycline $\left(10 \mu \mathrm{g} \mathrm{ml}^{-1}\right)$, chloramphenicol $\left(25\right.$ and $\left.100 \mu \mathrm{g} \mathrm{ml}^{-1}\right)$ and kanamycin $\left(10 \mu \mathrm{g} \mathrm{ml}^{-1}\right)$.

All isolates were tested for their ability to grow in purified sand at the expense of intact, living hyphae of the fungi Mucor hiemalis, Chaetomium globosum and Fusarium culmorum (De Boer et al., 2001). Growth response of bacteria was determined 3 weeks after introduction of the fungal inoculum. In zones where hyphae were present, bacterial numbers were determined by plate-counting and corrected for numbers that were present in the controls (i.e. without fungal invasion).

DNA G+C content. Genomic DNA isolation was performed by using Qiagen genomic-tips 500/G according to the manufacturer's recommendations. Determination of $\mathrm{G}+\mathrm{C}$ content was carried out on four isolates (Ter6 ${ }^{\mathrm{T}}$, Ter10, Ter252 and Ter331) by using thermal denaturation, as described by Marmur \& Doty (1962).

BOX-PCR. BOX-PCR genomic fingerprinting was performed by using the method described by Rademaker \& de Bruijn (1997). DNA was extracted from $3 \mathrm{ml}$ liquid culture by a standard minichromosomal DNA extraction method (Sambrook et al., 1989). Genomic fingerprints were compared by using the program IMAGE MASTER 1D ELITE (version 4.20; Amersham Pharmacia). Cluster analysis of pairwise similarity values was performed by using the UPGMA algorithm (Sneath \& Sokal, 1973).

Cloning, sequencing and phylogenetic analysis. Almostcomplete sequences of $16 \mathrm{~S}$ rRNA genes were determined commercially by the Centraalbureau voor Schimmelcultures (CBS), Utrecht, the Netherlands. A $5 \mu \mathrm{l}$ aliquot of a colony resuspended in Tris/ EDTA buffer was spotted onto CloneSaverCards (Whatman Bioscience) according to the manufacturer's recommendations. PCR was performed on $1.2 \mathrm{~mm}$ punches of the card with primers $16 \mathrm{~S} 1500 \mathrm{~F}$ ( $5^{\prime}$-ccgaattcgtcgacaacagagtttgatcctggctcag- $\left.3^{\prime}\right)$ and $16 \mathrm{~S} 1500 \mathrm{R}$ $\left(5^{\prime}\right.$-cccgggatccaagcttacggctaccttgttacgactt- $\left.3^{\prime}\right)$. PCR products were cleaned by using GFX columns (Amersham Biosciences) and sequenced by using DYE-ET terminator cycle sequencing (Amersham Biosciences) with the following primers (sequences in $5^{\prime} \rightarrow 3^{\prime}$ direction): 16S500F (tggagagtttgatcctggctcag), 16S500R (taccgcggctgctggcac), BSF1099/16 (gyaacgagcgcaaccc), BSF349/17 (aggcagcagtggggaat), 
BSF748/15 (rggattagatacccc), BSF8/20 (agagtttgatcctggctcag), BSR1114/ 16 (gggttgcgctcgttrc), BSR357/15 (ctgctgcctyccgta) and BSR798/15 (ggggtatctaatccc). Prior to separation on an ABI 3700 system (Applied Biosystems), sequencing products were purified by using Sephadex G-50 Superfine. Contigs were built with the DNASTAR package and the Phrap/Phred/Consed package (http://www.phrap.org/).

Sequence alignments were performed by using CLUSTAL_W (Thompson et al., 1994). Trees were constructed by using the neighbour-joining method.

Sequence similarity searches with previously determined database entries were performed with the BLAST program as supported by the NCBI website (Altschul et al., 1997; http://www.ncbi.nlm.nih.gov/blast).

Design of a Collimonas-specific FISH (fluorescent in situ hybridization) probe. The $16 \mathrm{~S}$ rDNA sequences of all Ter isolates were aligned and the consensus sequence was compared to $16 \mathrm{~S}$ rDNA sequences of members of the family 'Oxalobacteraceae'. One unique continuous stretch of 18 bp was shared between all Ter isolates, but was absent in all other strains. A probe complementary to this sequence was designed (CTE998-1015: 5'-CTCTTCGGGATTCTGTAC-3') and was found to be unique in a search of more than 72000 sequences by using the PROBE_MATCH program of Ribosomal Database Project II (http://rdp.cme.msu.edu/cgis/probe_match. cgi?su $=\mathrm{SSU}$ ). The probe was synthesized, labelled with Cy3 (Thermo Hybaid) and tested by FISH analysis on paraformaldehyde-fixed cells of all Ter isolates and three Herbaspirillum strains (Egli et al., 2001).

\section{RESULTS AND DISCUSSION}

\section{Morphological characteristics}

On chitin/yeast agar, halo formation as a result of chitin degradation by the Ter isolates was detected after 5-7 days incubation at $20^{\circ} \mathrm{C}$. Haloes reached a final size of 4-10 mm after about 14 days. As the isolates produced translucent biomass in small amounts, the colonies and surrounding haloes appeared as clear spots. On $0 \cdot 1 \times$ TSB agar, three different colony types were observed. Nine isolates, including the designated type strain, Ter $6^{\mathrm{T}}$, produced type I colonies, which appeared as flat, glossy, turbid, whitish colonies with a diameter of 3-7 $\mathrm{mm}$ and a layered structure. Type II colonies (five isolates) were flat with a diameter of 3-7 mm, a yellowish central part and a translucent, granular-structured periphery. The remaining eight isolates grew as small, glossy, whitish colonies with a diameter of 1-3 mm (type III).

Light and electron microscopic observations showed that the cell morphology of all colony types of Ter isolates was very similar. They were straight or slightly curved rods, $0 \cdot 3-0 \cdot 5 \mu \mathrm{m}$ in diameter and $1 \cdot 0-2 \cdot 0 \mu \mathrm{m}$ long (Fig. 1). Transmission electron microscopic inspection demonstrated the presence of one to three polar flagella and pili (Fig. 1a). In some instances, lateral flagella were also seen. Presence of flagella was, however, only observed when the isolates were grown in liquid media. Most cells produced polyphosphate granules (about $0 \cdot 1 \mu \mathrm{m}$ diameter) in the media used. Transmission electron micrographs further indicated that the cell-wall ultrastructure was Gramnegative, which was confirmed by $\mathrm{KOH}$ tests.

Most Ter isolates were highly motile on low-percentage agar plates, with a rate of $>40 \mathrm{~mm}$ in $48 \mathrm{~h}$. Isolates that belonged to colony type III were less motile (spreading $<20 \mathrm{~mm}$ in $48 \mathrm{~h}$ ).

\section{Growth characteristics}

A summary of growth characteristics (Supplementary Table A) is available as in IJSEM Online. None of the nine Ter isolates tested was able to grow under anaerobic conditions. These isolates were positive for oxidase and negative or weakly positive for catalase.

Four isolates $\left(\mathrm{Ter}^{\mathrm{T}}\right.$, Ter146, Ter227 and Ter331) were selected for testing the effects of environmental conditions on growth. These isolates had a broad temperature optimum; highest growth rates were observed at $20-30{ }^{\circ} \mathrm{C}$. Growth rates decreased gradually at lower temperatures (minimum temperature, $<4^{\circ} \mathrm{C}$ ), but dropped dramatically

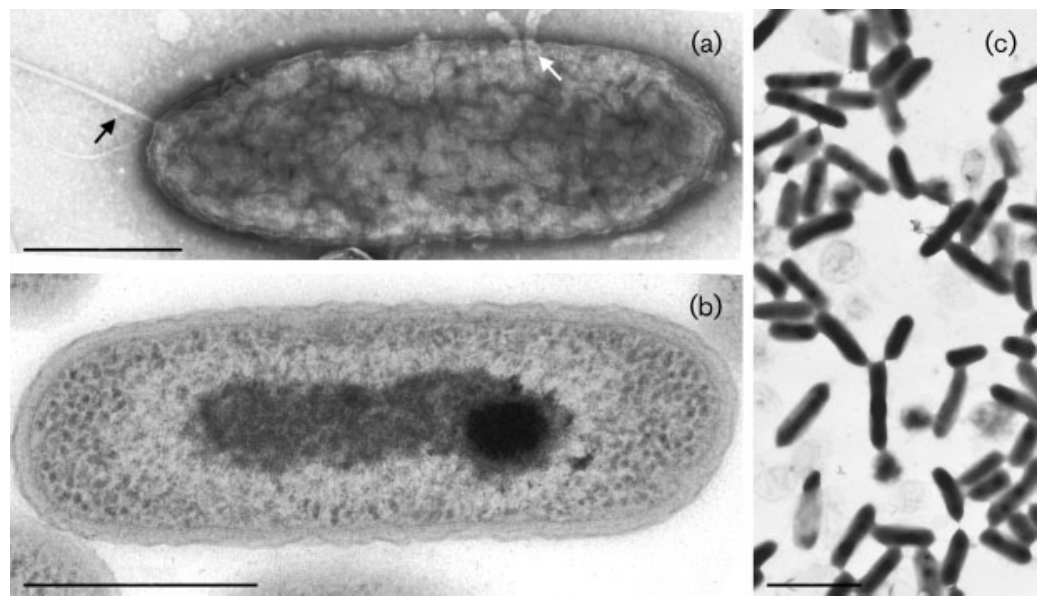

Fig. 1. Transmission electron micrographs of Ter isolates (Collimonas) grown on chitin/ yeast agar, showing: (a) a polar flagellum (black arrow) and pili (white arrow) of cells (Ter331) grown in liquid culture (bar, $0.5 \mu \mathrm{m}$ ); (b) Gram-negative cell-wall structure (Ter227) and polyphosphate granules (bar, $0.5 \mu \mathrm{m}$ ); and (c) general cell morphology (Ter6 ${ }^{\top}$, negatively stained) (bar, $\left.1 \mu \mathrm{m}\right)$. 
at temperatures above $35^{\circ} \mathrm{C}$. Optimal $\mathrm{pH}$ for growth was $6 \cdot 5$, but the effect of $\mathrm{pH}$ on growth was minor within the range studied $(5 \cdot 0-8 \cdot 0)$.

All Ter isolates were able to hydrolyse colloidal chitin in solid and liquid minimal media. The rate of chitin hydrolysis in liquid media was relatively slow for isolates that belonged to colony type III (not shown). None of the isolates hydrolysed colloidal chitin in agar that contained TSB, possibly due to catabolic repression. Catabolic repression of chitinase production has been reported for several bacteria, e.g. Cytophaga, Arthrobacter and Streptomyces (Morrissey et al., 1976; De Boer et al., 1998; Saito et al., 1998). However, in contrast to most other soil and rhizosphere bacteria, repression of chitinase activity of the Ter isolates on mixed chitin/TSB agar was complete and long-lasting (De Boer et al., 1998; W. de Boer \& P. J. A. Klein Gunnewiek, unpublished results).

Chitosanase activity was observed in about half of the isolates. All isolates were proteolytic, but did not show glucanolytic or cellulolytic activity under the conditions tested.

All Ter isolates proliferated in sand when hyphae of the fungi C. globosum, F. culmorum or M. hiemalis invaded. The strongest increase in cells was induced by hyphae of M. hiemalis. All isolates adhered rapidly to heat-fixed hyphae of the three fungi, as observed by microscopic inspection (not shown).

Growth of the Ter isolates on TSB agar was not inhibited by ampicillin $\left(60 \mu \mathrm{g} \mathrm{ml}^{-1}\right)$, streptomycin $\left(25 \mu \mathrm{g} \mathrm{ml}^{-1}\right)$, chloramphenicol $\left(25 \mu \mathrm{g} \mathrm{ml}^{-1}\right)$ or kanamycin $\left(10 \mu \mathrm{g} \mathrm{ml}^{-1}\right)$. Oxytetracycline $\left(10 \mu \mathrm{g} \mathrm{ml}^{-1}\right)$ inhibited all but two isolates (Ter146 and Ter300).

\section{Phylogenetic position based on 165 rDNA nucleotide sequences}

Comparison of nearly full-length $16 \mathrm{~S}$ rDNA sequences (corresponding to Escherichia coli positions 68-1451) of all 22 Ter isolates revealed between 98.6 and $99.9 \%$ similarity. Taking into account only those nucleotides that were phylogenetically informative, 12 unique $16 \mathrm{~S}$ rDNA sequences could be distinguished that were related most closely to representatives of the genera Herbaspirillum (95.9-96.7\% similarity) and Janthinobacterium (94.3$95.6 \%$ similarity) (Fig. 2). These genera belong to the family 'Oxalobacteraceae', order 'Burkholderiales' (Garrity et al., 2001). Another close relative is a hydrogen-oxidizing isolate designated Aquaspirillum autotrophicum (Aragno \& Schlegel, 1978). This isolate, however, does not show a close affiliation with other Aquaspirillum species, including the genus-defining species Aquaspirillum serpens. Ding \& Yokota (2002) demonstrated that the genus Aquaspirillum is polyphyletic, with at least four proposed phylogenetic groupings, including placement of A. autotrophicum in the family 'Oxalobacteraceae'. Therefore, re-evaluation of the phylogenetic position of A. autotrophicum is needed.

The Cy3-labelled probe CTE998-1015 hybridized to all fixed cells of Ter isolates at $45^{\circ} \mathrm{C}, 10 \%$ formamide, but not to cells of $H$. frisingense, $H$. rubrisubalbicans or $H$. seropedicae (not shown).

\section{Metabolic profile}

The Ter isolates had a similar respiratory response to 80 of the 95 substrates in the Biolog GN plates. Substrates that induced respiratory activity were: Tween 40, Tween 80 , acetyl-D-glucosamine, L-arabinose, D-arabitol, D-fructose,

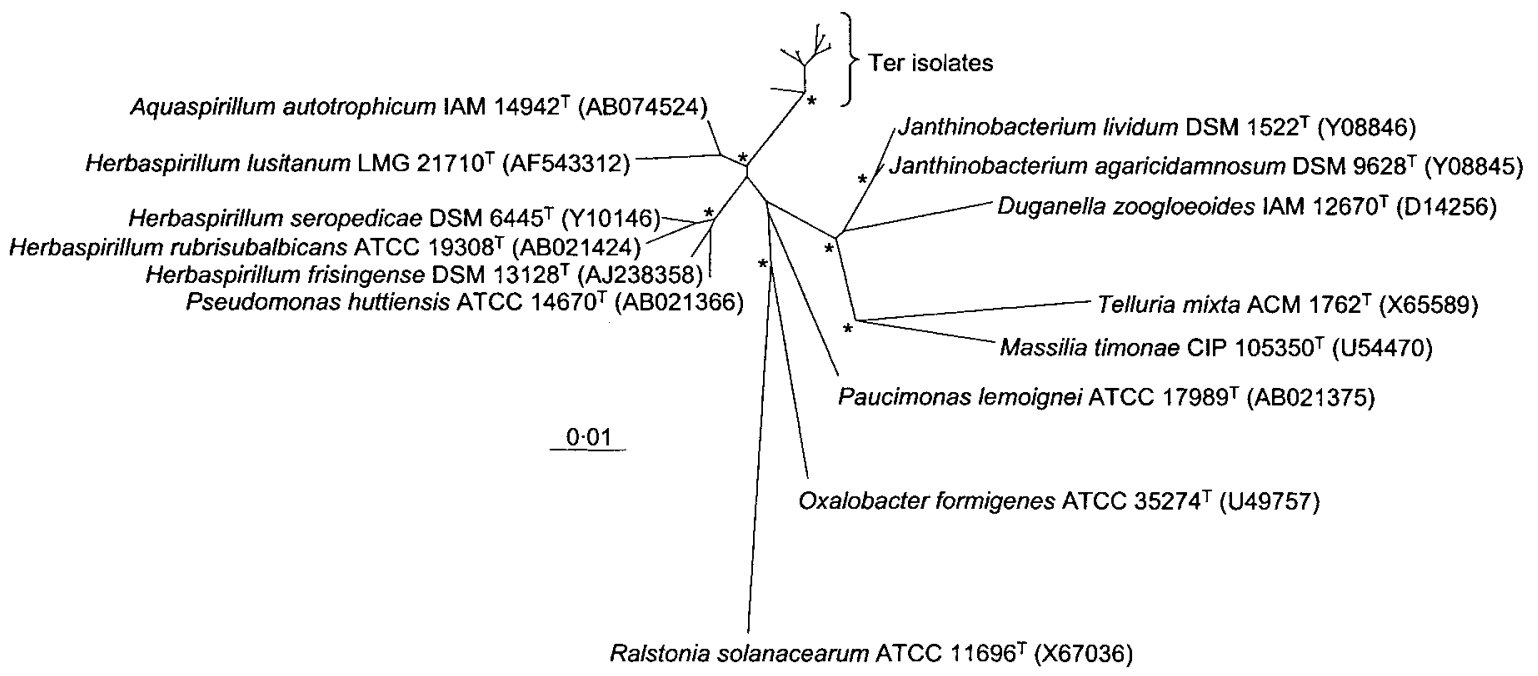

Fig. 2. Unrooted tree showing the phylogenetic relationship between the 12 unique $16 \mathrm{~S}$ rDNA sequences of 22 Ter isolates (Collimonas) and other members of the family 'Oxalobacteraceae'. The 16S rDNA sequence of Ralstonia solanacearum ATCC $11696^{\top}$ (GenBank no. X67036) was used as the outgroup. Tree construction was by neighbour-joining. Asterisks indicate nodes with bootstrap values of 950 or higher (1000 replicates). Bar, $0 \cdot 01$ nucleotide substitutions. 
L-fucose, D-galactose, D-glucose, $m$-inositol, D-mannitol, D-mannose, methyl pyruvate, monomethyl succinate, acetic acid, cis-acetonic acid, citric acid, formic acid, D-galactonic acid lactone, D-gluconic acid, D-glucuronic acid, $\beta$-hydroxybutyric acid, $\alpha$-ketoglutaric acid, DL-lactic acid, propionic acid, D-saccharic acid, succinic acid, bromosuccinic acid, alaninamide, L-alanine, L-alanylglycine, L-aspargine, L-aspartic acid, L-glutamic acid, glycyl L-glutamic acid, L-leucine, L-proline, L-pyroglutamic acid, L-threonine, $\gamma$-aminobutyric acid, inosine, uridine and glycerol. Substrates that were negative or gave very weak respiratory activity were: $\alpha$-cyclodextrin, dextrin, glycogen, acetyl-D-galactosamine, cellobiose, $m$-erythritol, gentiobiose, $\alpha$-D-lactose, maltose, D-melibiose, methyl $\beta$-Dglucoside, D-psicose, raffinose, L-rhamnose, sucrose, turanose, $\alpha$-hydroxybutyric acid, $\gamma$-hydroxybutyric acid, hydroxyphenylacetate, itaconic acid, $\alpha$-ketobutyric acid, $\alpha$-ketovaleric acid, malonic acid, sebacic acid, D-alanine, glycyl L-aspartic acid, hydroxy-L-proline, L-ornithine, L-phenylalanine, D-serine, DL-carnitine, thymidine, phenylethylamine, putrescine and glucose 1-phosphate. The isolates varied for (responses for strain Ter6 $^{\mathrm{T}}$ are given in parentheses): adonitol $(-)$, lactulose $(+)$, D-sorbitol $(+)$, D-trehalose $(+)$, xylitol $(+)$, D-galacturonic acid $(-)$, D-glucosamic acid $(-)$, quinic acid $(-)$, succinamic acid $(-)$, glucuronamide $(-)$, L-histidine $(-)$, L-serine $(-)$,

Table 1. Differentiating respiratory activities (Biolog GN) of Ter isolates (Collimonas) and Herbaspirillum and Janthinobacterium strains

Taxa: 1, Herbaspirillum; 2, Janthinobacterium; 3, Ter isolates. +, Activity present in all isolates; $\mathrm{M}$, present in most isolates (>90\%); L, present in $<10 \%$ of isolates; - , not present; $\mathrm{V}$, variable among isolates.

\begin{tabular}{|lccc|}
\hline Substrate & $\mathbf{1}^{\star}$ & $\mathbf{2}^{\dagger}$ & $\mathbf{3}$ \\
\hline Adonitol & + & - & $\mathrm{L}$ \\
D-Trehalose & - & $\mathrm{V}$ & $\mathrm{M}$ \\
Monomethyl succinate & + & - & + \\
cis-Aconitic acid & + & - & + \\
D-Galacturonic acid & + & - & $\mathrm{L}$ \\
Itaconic acid & + & - & - \\
D-Saccharic acid & + & - & + \\
Glycyl L-glutamic acid & - & + & + \\
L-Histidine & - & - & $\mathrm{M}$ \\
L-Leucine & + & - & + \\
Inosine & - & $\mathrm{V}$ & + \\
Uridine & - & - & + \\
Glucose 1-phosphate & - & + & - \\
\hline
\end{tabular}

${ }^{\star}$ Tests carried out with three type strains (H. seropedicae DSM $6445^{\mathrm{T}}$, H. rubrisubalbicans ATCC $19308^{\mathrm{T}}$ and H. frisingense DSM $13128^{\mathrm{T}}$ ) and complemented with data given by Baldani et al. (1996) and Lincoln et al. (1999).

$\nmid$ Data from Lincoln et al. (1999) for three strains each of Janthinobacterium lividum and Janthinobacterium agaricidamnosum. 2-aminoethanol $(+)$, DL-glycerol phosphate $(-)$, glucose 6-phosphate $(-)$ and urocanic acid $(+)$.

The metabolic profiles of the Herbaspirillum type strains were very similar to each other (not shown). Most notable differences between the Ter isolates and the Herbaspirillum strains were found in the metabolism of itaconic acid, glycyl L-glutamic acid, inosine and uridine (Table 1). Furthermore, none of the Herbaspirillum strains was able to degrade colloidal chitin.

From Table 1, it can be seen that the Ter isolates share some metabolic properties with Herbaspirillum strains and others with Janthinobacterium strains. However, the ability of the Ter isolates to metabolize uridine and L-histidine distinguishes them from both of these genera.

\section{Cellular fatty acid composition}

The cellular fatty acid composition of all Ter isolates is given in Table 2. In total, 13 fatty acids were found, of which eight were present in all isolates. The major fatty acids were $\mathrm{C}_{16: 0}$ and $\mathrm{C}_{16: 1} \omega 7 c$. The major cellular fatty acids of the three Herbaspirillum type strains were $\mathrm{C}_{16: 0}, \mathrm{C}_{16: 1} \omega 7 c$ and $\mathrm{C}_{18: 1} \omega 7 c$ (Table 2). The absence of the fatty acid $\mathrm{C}_{14: 0}$ $2-\mathrm{OH}$ in the Ter isolates is a characteristic that clearly distinguishes these strains from Herbaspirillum species (Table 2; Lincoln et al., 1999). Furthermore, the Ter isolates

Table 2. Cellular fatty acid composition (\%) of Ter isolates (Collimonas) and strains of Herbaspirillum and Janthinobacterium

Taxa: 1, Ter isolates $(n=22) ; 2$, Herbaspirillum $(n=3) ; 3$, Janthinobacterium $(n=6)$.

\begin{tabular}{|c|c|c|c|}
\hline Fatty acid ${ }^{\star}$ & 1 & $2 \dagger$ & $3 \ddagger$ \\
\hline $\mathrm{C}_{10: 0}$ & $0 \cdot 0-0 \cdot 4$ & $0 \cdot 1-0 \cdot 2$ & - \\
\hline $\mathrm{C}_{10: 0} 3-\mathrm{OH}$ & $0 \cdot 8-1 \cdot 2$ & $1 \cdot 5-1 \cdot 6$ & $3 \cdot 1-4 \cdot 0$ \\
\hline $\mathrm{C}_{12: 0}$ & $3 \cdot 1-4 \cdot 0$ & $0 \cdot 5-3 \cdot 1$ & $3 \cdot 6-5 \cdot 2$ \\
\hline $\mathrm{C}_{12: 0} 2-\mathrm{OH}$ & $2 \cdot 2-2 \cdot 8$ & $0 \cdot 5-1 \cdot 4$ & $0 \cdot 0-0 \cdot 9$ \\
\hline $\mathrm{C}_{12: 0} 3-\mathrm{OH}$ & $3 \cdot 1-3 \cdot 9$ & $3 \cdot 1-3 \cdot 5$ & - \\
\hline $\mathrm{C}_{14: 0}$ & $0 \cdot 0-0 \cdot 6$ & $0 \cdot 6-3 \cdot 8$ & $0 \cdot 6-3 \cdot 8$ \\
\hline $\mathrm{C}_{14: 0} 2-\mathrm{OH}$ & - & $1 \cdot 1-2 \cdot 2$ & - \\
\hline $\mathrm{C}_{16: 0}$ & $30 \cdot 8-41 \cdot 2$ & $21 \cdot 3-26 \cdot 5$ & $35 \cdot 3-40 \cdot 9$ \\
\hline $\mathrm{C}_{16: 1} \omega 7 c$ & $31 \cdot 8-42 \cdot 5$ & $29 \cdot 7-36 \cdot 0$ & $22 \cdot 4-40 \cdot 7$ \\
\hline $\mathrm{C}_{16: 1} 2-\mathrm{OH}$ & $0 \cdot 0-4 \cdot 7$ & $0 \cdot 4-0 \cdot 5$ & - \\
\hline $\mathrm{C}_{17: 0}$ & $0 \cdot 0-0 \cdot 7$ & $0 \cdot 2-0 \cdot 4$ & - \\
\hline $\mathrm{C}_{17: 0}$ cyclo & $0 \cdot 7-5 \cdot 2$ & $4 \cdot 6-10 \cdot 0$ & $9 \cdot 8-26 \cdot 7$ \\
\hline $\mathrm{C}_{18: 0}$ & $0 \cdot 0-1 \cdot 5$ & $1 \cdot 0-1 \cdot 2$ & - \\
\hline $\mathrm{C}_{18: 1} \omega 7 c$ & $7 \cdot 1-14 \cdot 9$ & $21 \cdot 2-23 \cdot 6$ & $1 \cdot 4-3 \cdot 5$ \\
\hline
\end{tabular}

${ }^{*}$ Fatty acids given in bold are distinctive between the genera.

$\dagger$ Data for $H$. seropedicae DSM $6445^{\mathrm{T}}, H$. rubrisubalbicans ATCC $19308^{\mathrm{T}}$ and $H$. frisingense DSM $13128^{\mathrm{T}}$.

¥Data from Lincoln et al. (1999) for three strains each of Janthinobacterium lividum and Janthinobacterium agaricidamnosum. 
had a much lower content of $\mathrm{C}_{18: 1} \omega 7 \mathrm{c}$ than Herbaspirillum species.

Comparison with data given by Lincoln et al. (1999) indicated that the Ter isolates contain more $\mathrm{C}_{18: 1} \omega 7 c$ than Janthinobacterium species, whereas the $\mathrm{C}_{17: 0}$ cyclo content of the Ter isolates was considerably lower than that of Janthinobacterium species (Table 2). The content of $\mathrm{C}_{12: 0}$ 2-OH of the Ter isolates was relatively high, compared to both Herbaspirillum and Janthinobacterium species, whereas their $\mathrm{C}_{10: 0} 3-\mathrm{OH}$ content was relatively low.

\section{DNA G+C content}

The DNA G $+\mathrm{C}$ content ( $T_{\mathrm{m}}$ method) of four isolates, including strain $\operatorname{Ter}^{\mathrm{T}}$ and representatives of each of the three colony types, varied from 57 to $62 \mathrm{~mol} \%\left(\right.$ Ter6 $^{\mathrm{T}} \mathrm{G}+\mathrm{C}$ content was $57 \cdot 8 \mathrm{~mol} \%$ ). This is notably lower than the $\mathrm{G}+\mathrm{C}$ contents of recognized species of Herbaspirillum and Janthinobacterium, with the exception of Herbaspirillum lusitanum (Valverde et al., 2003).

\section{Genomic and metabolic variation among the Ter isolates}

The 12 unique $16 \mathrm{~S}$ rDNA sequences among the $22 \mathrm{Ter}$ isolates clustered in four groups (see Supplementary Fig. A in IJSEM Online). This clustering was in perfect agreement with the genomic variation observed among the isolates by using BOX-PCR (see Supplementary Fig. B in IJSEM Online).

The BOX-PCR grouping could also be distinguished by comparing the respiratory response to four Biolog substrates and chitosan (data available as Supplementary Table B in IJSEM Online).

\section{Evaluation of phylogenetic position}

Given the high degree of $16 \mathrm{~S}$ rDNA sequence similarity to representatives of the genera Herbaspirillum (95.9-96.7\%) and Janthinobacterium (94.3-95.6\%), it could be argued that the Ter isolates belong to one or more novel species within one of these genera. However, as shown above, the Ter isolates do not match several basic biochemical and physiological characteristics of these genera (Tables 1 and 2 ). In addition, the Ter isolates differ from recognized Herbaspirillum species by lacking the ability to fix nitrogen (V. M. Reis, personal communication). Furthermore, unlike recognized Herbaspirillum species, the Ter isolates are soil bacteria with no apparent pathogenic or symbiotic relationship with plants (Baldani et al., 1996; Kirchhof et al., 2001; Valverde et al., 2003). The Ter isolates have a smaller cell size $(0 \cdot 3-0.5 \times 1 \cdot 0-2 \cdot 0 \mu \mathrm{m})$ than Janthinobacterium species $(0 \cdot 8-1.5 \times 1 \cdot 8-6.0 \mu \mathrm{m})$ (Sneath, 1984). None of the Ter isolates produced a purple pigment (violacein), which has been described as characteristic of the genus Janthinobacterium (Sneath, 1984). However, the species Janthinobacterium agaricidamnosum also does not produce this pigment (Lincoln et al., 1999). The Ter isolates are negative or weakly positive for catalase, whereas Janthinobacterium strains are positive (Lincoln et al., 1999). Given these differences with the genera Herbaspirillum and Janthinobacterium, it is proposed that the isolates should be assigned to a novel genus, Collimonas gen. nov. It should be noted that $16 \mathrm{~S}$ rDNA sequence similarity between species of the genera Herbaspirillum and Janthinobacterium is also high $(>96 \%)$ but, as discussed by Lincoln et al. (1999), morphological, physiological, chemical and ecological characteristics are so different that it would be unrealistic to combine these two genera. The same holds true for the genus Paucimonas (formerly Pseudomonas lemoignei), which has $95 \cdot 0-95 \cdot 9 \% 16 \mathrm{~S}$ rDNA sequence similarity with Herbaspirillum species (Jendrossek, 2001).

The highest level of sequence similarity between Collimonas strains and previously described $16 \mathrm{~S}$ rDNA sequences was found for GenBank entry AY154366 (98.9-99.6\%), which represents a naphthalene-degrading strain from the USA that was classified as Herbaspirillum sp. $\mathrm{Hg}$ (Wilson et al., 2003). Given its close affinity with Collimonas and much lower similarity with Herbaspirillum species $(<96.4 \%)$, it would be interesting to determine whether other characteristics of this strain might support its placement within Collimonas, thereby extending the known range of this genus.

Although comparison of $16 \mathrm{~S}$ rDNA sequences of the Ter isolates revealed that their interrelatedness was very high $(98 \cdot 6-99 \cdot 9 \%$ similarity), this is not sufficient to place them into a single species (Stackebrandt \& Goebel, 1994). As shown above, four subclusters can be recognized on the basis of $16 \mathrm{~S}$ rDNA sequences, genomic fingerprinting and substrate utilization (data available as supplementary material in IJSEM Online). This genomic and phenotypic variation forms the basis for establishing the centre and breadth of the novel genus (Christensen et al., 2001). Subcluster A, which contains strains with colony type II morphology, is most distant from the other isolates and consists of four isolates with identical $16 \mathrm{~S}$ rDNA sequences and BOX-PCR patterns. These Collimonas isolates are related most closely to the genus Herbaspirillum $(96 \cdot 2-$ $96.7 \%$ 16S rDNA sequence similarity). The other Collimonas subclusters are related more closely to each other and, as they represent the majority of isolates, it is from these subclusters that the type species should be chosen. As suggested by Christensen et al. (2001), the type species and strain is selected for pragmatic reasons, i.e. it should be most representative with respect to the characters that define the novel taxon. Based on the central position of the $16 \mathrm{~S}$ rDNA sequences, the mean value of fatty acid contents and the most common metabolic profile, cluster $\mathrm{C}$ (four isolates) has been selected to represent Collimonas fungivorans gen. nov., sp. nov. $\operatorname{Ter}^{\mathrm{T}}\left(=\mathrm{NCCB} 100033^{\mathrm{T}}\right.$ $=\mathrm{LMG} 21973^{\mathrm{T}}$ ) is the type strain.

\section{Description of Collimonas gen. nov.}

Collimonas (Col.li.mo'nas. L. masc. n. collis hill; Gr. n. monas a unit, monad; N.L. fem. n. Collimonas cell from the hill). 
Cells are strictly aerobic, straight or slightly curved, Gramnegative rods, $0 \cdot 3-0.5 \times 1 \cdot 0-2.0 \mu \mathrm{m}$. They occur singly and possess flagella (mostly one to three polar, but in some cases, several lateral) and pili when cultured in liquid media. Oxidase activity is positive; catalase activity is negative or weakly positive. Maximal growth is observed between 20 and $30^{\circ} \mathrm{C}$, without a sharp optimum. Maximum temperature that supports growth is approximately $35^{\circ} \mathrm{C}$. Optimal growth occurs at $\mathrm{pH} 6 \cdot 5$. Cells are able to hydrolyse colloidal chitin and milk proteins, but not lichenan or cellulose. Isolates vary in their ability to hydrolyse colloidal chitosan (deacetylated chitin). On minimal colloidal chitin/yeast agar, circular cleared haloes (final diameter, $4-10 \mathrm{~mm}$ ) that support little translucent biomass are produced. Halo formation is completely repressed in chitin agar that contains TSB or glucose. On $0 \cdot 1 \times$ TSB agar, colony morphology is variable. A wide range of sugars, alcohols, organic acids and amino acids can be metabolized. Several di- and trisaccharides cannot be used as substrates. In purified sand, cells proliferate upon introduction of intact, living fungal hyphae of various species of soil fungi. Major cellular fatty acids are $\mathrm{C}_{16: 0}$ and $\mathrm{C}_{16: 1} \omega 7 c$. DNA G $+\mathrm{C}$ content is $57-62 \mathrm{~mol} \%$. A member of the $\beta$-Proteobacteria, related most closely to the genera Herbaspirillum and Janthinobacterium in the family 'Oxalobacteraceae', order 'Burkholderiales'. Characteristics useful to differentiate the genus Collimonas from these related genera are given in Tables 1 and 2, as well as in the Results and Discussion. So far, the genus Collimonas is only known to occur in slightly acidic sandy dune soils. The type species is Collimonas fungivorans.

\section{Description of Collimonas fungivorans sp. nov.}

Collimonas fungivorans (fun.gi.vo' rans. L. n. fungus mould, mushroom, fungus; L. part. adj. vorans devouring, eating; N.L. part. adj. fungivorans fungus-eating).

General characteristics are the same as given above for the genus. On $0 \cdot 1 \times \mathrm{TSB}$ agar $\left(3\right.$ days, $\left.20^{\circ} \mathrm{C}\right)$, the type strain forms flat, glossy, turbid, whitish colonies of 3-7 mm diameter with a layered structure (colony type I; see Results and Discussion). Catalase activity is negative. Colloidal chitosan is hydrolysed. The substrate-use profile of the type strain is given above. The $\mathrm{G}+\mathrm{C}$ content of the type strain is $57 \cdot 8 \mathrm{~mol} \%$.

The type strain is $\operatorname{Ter}^{\mathrm{T}}\left(=\right.$ NCCB $\left.100033^{\mathrm{T}}=\mathrm{LMG} 21973^{\mathrm{T}}\right)$. Reference strains are Ter166, Ter300 and Ter330.

\section{ACKNOWLEDGEMENTS}

We thank Professor Hans Trüper (University of Bonn) for his help with Latin nomenclature and etymology. Ineke van den Beld, Plant Protection Service Wageningen, is acknowledged for performing the BOX-PCR analysis. Thanks to Gé Poot (CBS) for help with the $\mathrm{G}+\mathrm{C}$ determination. Dr Michael Schmid (GSF - Neuherberg) is acknowledged for supplying us with the Herbaspirillum strains. This is publication 3258 NIOO-KNAW of the Netherlands Institute of Ecology.

\section{REFERENCES}

Altschul, S. F., Madden, T. L., Schäffer, A. A., Zhang, J., Zhang, Z., Miller, W. \& Lipman, D. J. (1997). Gapped BLAST and PSI-BLAST: a new generation of protein database search programs. Nucleic Acids Res 25, 3389-3402.

Aragno, M. \& Schlegel, H. G. (1978). Aquaspirillum autotrophicum, a new species of hydrogen-oxidizing, facultatively autotrophic bacteria. Int J Syst Bacteriol 28, 112-116.

Baldani, J. I., Pot, B., Kirchhof, G. \& 8 other authors (1996). Emended description of Herbaspirillum; inclusion of [Pseudomonas] rubrisubalbicans, a mild plant pathogen, as Herbaspirillum rubrisubalbicans comb. nov.; and classification of a group of clinical isolates (EF group 1) as Herbaspirillum species 3. Int J Syst Bacteriol 46, 802-810.

Christensen, H., Bisgaard, M., Frederiksen, W., Mutters, R., Kuhnert, P. \& Olsen, J. E. (2001). Is characterization of a single isolate sufficient for valid publication of a new genus or species? Proposal to modify Recommendation 30b of the Bacteriological Code (1990 Revision). Int J Syst Evol Microbiol 51, 2221-2225.

De Boer, W., Klein Gunnewiek, P. J. A., Lafeber, P., Janse, J. D., Spit, B. E. \& Woldendorp, J. W. (1998). Anti-fungal properties of chitinolytic dune soil bacteria. Soil Biol Biochem 30, 193-203.

De Boer, W., Gerards, S., Klein Gunnewiek, P. J. A. \& Modderman, R. (1999). Response of the chitinolytic microbial community to chitin amendments of dune soils. Biol Fertil Soils 29, 170-177.

De Boer, W., Klein Gunnewiek, P. J. A., Kowalchuk, G. A. \& Van Veen, J. A. (2001). Growth of chitinolytic dune soil $\beta$-subclass Proteobacteria in response to invading fungal hyphae. Appl Environ Microbiol 67, 3358-3362.

Ding, L. \& Yokota, A. (2002). Phylogenetic analysis of the genus Aquaspirillum based on 16S rRNA gene sequences. FEMS Microbiol Lett 212, 165-169.

Egli, K., Fanger, U., Alvarez, P. J. J., Siegrist, H., van der Meer, J. R. \& Zehnder, A. J. B. (2001). Enrichment and characterization of an anammox bacterium from a rotating biological contactor treating ammonium-rich leachate. Arch Microbiol 175, 198-207.

Garrity, G. M., Winters, M. \& Searles, D. B. (2001). Taxonomic outline of the procaryotic genera. In Bergey's Manual of Systematic Bacteriology, 2nd edn, online release 1.0, April 2001. New York: Springer (http://www.cme.msu.edu/bergeys/april2001-genus.pdf).

Gooday, G. W. (1990). The ecology of chitin degradation. $A d v$ Microb Ecol 11, 387-430.

Hsu, S. C. \& Lockwood, J. L. (1975). Powdered chitin agar as a selective medium for enumeration of actinomycetes in water and soil. Appl Microbiol 29, 422-426.

Janse, J. D. (1991). Pathovar discrimination within Pseudomonas syringae subsp. savastanoi using whole cell fatty acid analysis and pathogenicity as criteria. Syst Appl Microbiol 14, 79-84.

Jendrossek, D. (2001). Transfer of [Pseudomonas] lemoignei, a Gramnegative rod with restricted catabolic capacity, to Paucimonas gen. nov. with one species, Paucimonas lemoignei comb. nov. Int J Syst Evol Microbiol 51, 905-908.

Kirchhof, G., Eckert, B., Stoffels, M., Baldani, J. I., Reis, V. M. \& Hartmann, A. (2001). Herbaspirillum frisingense sp. nov., a new nitrogen-fixing bacterial species that occurs in C4-fibre plants. Int J Syst Evol Microbiol 51, 157-168.

Lincoln, S. P., Fermor, T. R. \& Tindall, B. J. (1999). Janthinobacterium agaricidamnosum sp. nov., a soft rot pathogen of Agaricus bisporus. Int J Syst Bacteriol 49, 1577-1589. 
Marmur, J. \& Doty, P. (1962). Determination of the base composition of deoxyribonucleic acid from its thermal denaturation temperature. J Mol Biol 5, 109-118.

Morrissey, R. F., Dugan, E. P. \& Koths, J. S. (1976). Chitinase production by an Arthrobacter sp. lysing cells of Fusarium roseum. Soil Biol Biochem 8, 23-28.

Rademaker, J. L. W. \& de Bruijn, F. J. (1997). Characterization and classification of microbes by rep-PCR genomic fingerprinting and computer-assisted pattern analysis. In DNA Markers: Protocols, Applications, and Overviews, pp. 151-171. Edited by G. CaetanoAnollés \& P. M. Gresshoff. New York: Wiley.

Saito, A., Fujii, T., Yoneyama, T. \& Miyashita, K. (1998). glkA is involved in glucose repression of chitinase production in Streptomyces lividans. J Bacteriol 180, 2911-2914.

Sambrook, J., Fritsch, E. F. \& Maniatis, T. (1989). Molecular Cloning: a Laboratory Manual, 2nd edn. Cold Spring Harbor, NY: Cold Spring Harbor Laboratory.

Sneath, P. H. A. (1984). Genus Janthinobacterium De Ley, Seegers and Gillis 1978, 164 ${ }^{\mathrm{AL}}$. In Bergey's Manual of Systematic Bacteriology, vol. 1, pp. 376-377. Edited by N. R. Kreig \& J. G. Holt. Baltimore: Williams \& Wilkins.
Sneath, P. H. A. \& Sokal, R. R. (1973). Numerical Taxonomy: the Principles and Practice of Numerical Classification. San Francisco: Freeman.

Stackebrandt, E. \& Goebel, B. M. (1994). Taxonomic note: a place for DNA-DNA reassociation and 16S rRNA sequence analysis in the present species definition in bacteriology. Int J Syst Bacteriol 44, 846-849.

Thompson, J. D., Higgins, D. G. \& Gibson, T. J. (1994). CLUSTAL W: improving the sensitivity of progressive multiple sequence alignment through sequence weighting, position-specific gap penalties and weight matrix choice. Nucleic Acids Res 22, 4673-4680.

Valverde, A., Velázquez, E., Gutiérrez, C., Cervantes, E., Ventosa, A. \& Igual, J.-M. (2003). Herbaspirillum lusitanum sp. nov., a novel nitrogen-fixing bacterium associated with root nodules of Phaseolus vulgaris. Int J Syst Evol Microbiol 53, 1979-1983.

Walsh, G. A., Murphy, R. A., Killeen, G. F., Headon, D. R. \& Power, R. F. (1995). Detection and quantification of supplemental fungal $\beta$-glucanase activity in animal feed. J Anim Sci 73, 1074-1076.

Wilson, M. S., Herrick, J. B., Jeon, C. O., Hinman, D. E. \& Madsen, E. L. (2003). Horizontal transfer of phnAc dioxygenase genes within one of two phenotypically and genotypically distinctive naphthalenedegrading guilds from adjacent soil environments. Appl Environ Microbiol 69, 2172-2181. 